\section{Planting ideas in the literature}

\author{
Charlie Shaw and Phil Gates
}

The Plant Cell. Editor Robert B. Goldberg. American Society of Plant Physiologists. $12 / y r$. $\$ 550$ for The Plant Cell and Plant (institutional); $\$ 100$ (personal).

Sexual Plant Reproduction. Managing editor H.F. Linskens. Springer-Verlag. 4/yr. DM 270; North America \$160.

THE recent expansion in the plant sciences, particularly in molecular biological work, has largely gone unnoticed by the frontline publications such as Cell, Nature and Science. The paucity of 'plant' papers in these journals has contributed directly to the failure of animal and microbial scientists to recognize the massive advances made in plant molecular biology (there are, for example, more transgenic plants than animals in existence). The void has been partly filled by the excellent $E M B O$ Journal, which has always allocated a significant proportion of its space to 'plant' articles. Another, more specialized journal in this field is Plant Molecular Biology, but it has yet to reach real prominence.

Into the breach have stepped two new publications. The Plant Cell is a highimpact glossy journal, backed by the American Society of Plant Physiologists and sister to Plant Physiology. By the editor's own admission, Cell has been taken as the benchmark and the quality of reproduction, format and science are generally of a high standard. The journal was launched specifically to address the interface between molecular, cellular and developmental approaches in plants, and thus far it appears to be fulfilling this role. Most of the papers address molecular questions (the majority of them also involving some element of cell biology and development) and most concern higher plants, though the journal also aims to cover fungi and protists relevant to plant problems.

The editor is meeting his goal of rapid publication (six to eight weeks from acceptance to publication). He has also shown that he is not afraid of controversy by entering into the debate over a leading article in Cell, which prefaced an issue belatedly devoted to plant reviews and which was patronizing in tone and poorly researched. The Plant Cell has already attracted a good number of subscriptions and looks set for a healthy future, although the decline in issue size is disturbing and more colour figures and cellular/developmental papers are needed. Unless other high-profile journals increase their 'green' content, it should become the place that all plant molecular biologists look to first.

Papers on such varied topics as pollen transformation, sexual induction in Volvox, pollination methods for lily hybridization and a review on thermogenicity in Arum have appeared in the first few issues of Sexual Plant Reproduction, confirming the editors' stated intention to reflect the transdisciplinary nature of research in plant reproduction. Hitherto, published work on the subject has been widely dispersed in the literature. This new journal, with an editorial board that constitutes a who's who of research workers in the field, should act as a catalyst to greater progress in our under-

\section{Off target}

\section{Peter H. Williams}

Molecular Microbiology. Editors Chris Higgins and Gary Schoolnik. Blackwell Scientific. 12/yr. UK £210, North America \$395, elsewhere $£ 241$ (institutional); UK £69, North America \$132, elsewhere $£ 79.50$ (personal).

THERE is something unequivocal and uncompromising, even menacing, about the title Molecular Microbiology. It permits no ambiguity. Not for me, it seems to say, the sweeping breadth of the Journal of General Microbiology or the Journal of Bacteriology; none of the vagueness suggested by Infection and Immunity or the Journal of Infectious Diseases. If your work is both molecular and microbiological, it says, then this is the place for you; if not, bug off.

The scope of the journal is simply and precisely what the title says it is - molecular aspects (protein structure, enzymology, immunology, gene organization and mapping, regulation, DNA topology and so on) of micro-organisms from Anabaena to Yersinia (doesn't anyone work on Zymomonas?), with, it has to be said, an emphasis on pathogenicity. Papers can be anything from 1,400 to 7,000 words long, although most are much less than the upper limit, short review articles ("MicroReviews"!) are invited on topics of particular current interest, and each issue bears a cover photograph (generally in colour) relevant to one of the papers it contains. Notes of up to 2,500 words are also accepted. But their format is so like that of a regular paper, and the speed of publication not significantly faster, that there seems little advantage in having a distinct category.

Acceptable manuscripts appear in print a creditable six to seven months after standing of plant reproductive processes at every level.

New techniques in plant molecular biology have already advanced our understanding of reproductive processes, building on foundations laid by biochemists, physiologists and geneticists, and it is slightly worrying that several relevant molecular biological papers have appeared in The Plant Cell, rather than Sexual Plant Reproduction. It would be a pity if the Springer journal's potential role in integrating knowledge from widely varying experimental disciplines were to be prejudiced by molecular-orientated authors being dazzled by the high-impact format of The Plant Cell.

Charlie Shaw and Phil Gates are in the Department of Biological Sciences, University of Durham, South Road, Durham DH1 3LE, UK.

submission, and, unlike the journals of the American Society for Microbiology that constitute its main rivals, there are no handling charges and the first 50 reprints are free. So far, the general quality of the articles has been very high, in terms of both scientific merit and standard of writing. The quality of presentation is also excellent; the layout, with well-spaced lines and text in two columns per page, is particularly attractive and easy to read, and the cover pictures are eye-catching, if not always very original. If quality alone is the recipe for success, then this new journal is here to stay. But is it?

The problem, it seems to me, is that Molecular Microbiology cannot be said to fill a gap. Its scope is almost identical to that of Microbial Pathogenicity (another newcomer currently emphasizing molecular studies), and all the papers published so far would have found appropriate resting places in other journals of broader appeal. Molecular Microbiology claims on its cover to incorporate Microbiological Sciences, a journal that successfully disseminated the message of new technology in well-written reviews to a wide, nonspecialist audience. In changing its name, this journal has also changed its nature to the extent that it no longer fulfils this function; it is now aimed unashamedly at a well-defined cross-disciplinary group which includes microbiologists who ask molecular questions and molecular biologists who happen to work with micro-organisms.

Surely, though, the real target of much of the work published here is, or should be, future practitioners of molecular methods - clinical microbiologists, for example, who may not yet be asking molecular questions, but who would be if the relevant information were intelligibly presented. I fear that Molecular Microbiology may have missed this target.

Peter H. Williams is in the Department of Genetics, University of Leicester, University Road, Leicester LE1 7RH, UK. 